\title{
BMJ open Laterality, hand control and scholastic performance: a British birth cohort study
}

\author{
Tabita Björk, ${ }^{1,2}$ Ole Brus, ${ }^{3}$ Walter Osika, ${ }^{4}$ Scott Montgomery ${ }^{3,5,6,7}$
}

To cite: Björk T, Brus 0 , Osika W, et al. Laterality, hand control and scholastic performance: a British birth cohort study. BMJ Open 2012;2: 000314

doi:10.1136/

bmjopen-2011-000314

- Prepublication history and additional appendices for this paper are available online. To view these files please visit the journal online (http://dx. doi.org/10.1136/ bmjopen-2011-000314).

Received 18 August 2011 Accepted 30 January 2012

This final article is available for use under the terms of the Creative Commons Attribution Non-Commercial 2.0 Licence; see http://bmjopen.bmj.com

${ }^{1}$ Psychiatric Research Centre, Örebro County Council, Örebro, Sweden ${ }^{2}$ Department of Clinical Neuroscience, Division of Psychiatry, Karolinska Institutet, Stockholm, Sweden

${ }^{3}$ Clinical Epidemiology and Biostatistics Unit, Örebro University Hospital, Örebro, Sweden

${ }^{4}$ Stress Research Institute, Stockholm University, Stockholm, Sweden

${ }^{5}$ School of Health and Medical Sciences, Örebro University, Örebro, Sweden ${ }^{6}$ Clinical Epidemiology Unit, Karolinska Institutet,

Stockholm, Sweden

${ }^{7}$ Department of Primary Care and Public Health, Charing Cross Hospital, Imperial College, London, UK

Correspondence to Dr Tabita Björk; tabita.bjork@orebroll.se

\section{ABSTRACT}

Objectives: To use simple measures of laterality and hand control that can identify a greater risk of poorer scholastic ability, potentially signalling suboptimal hemispheric lateralisation.

Design: Analysis of material from a birth cohort study. Setting: Members of the National Child Development Study, a British birth cohort study following people born in 1958.

Participants: 10612 children who undertook tests at age 11 years.

Primary outcome measures: Teacher-administered tests of non-verbal general ability, verbal general ability, reading comprehension and mathematics.

Results: Linear regression produced associations (and $95 \% \mathrm{Cls}$ ) with tests of verbal general ability, nonverbal general ability, reading comprehension and mathematics scores for the lowest third (compared with highest) of a left-hand control test involving picking up matches of $-1.21(-1.73$ to -0.68 ; $\mathrm{p}<0.001),-0.72(-1.14$ to $-0.29 ; p=0.001),-0.70$ $(-1.06$ to $-0.35 ; p<0.001)$ and $-1.32(-1.90$ to $-0.73 ; p<0.001)$. Among those in the lowest third of the right-hand control test score, mixed-handedness compared with right-handedness was associated with poorer scholastic performance, with regression coefficients (and $95 \%$ Cls; $p$ values) of $1.90(-3.01$ to $-0.80 ; p=0.001),-1.25(-2.15$ to $-0.35 ; p=0.007)$, -1.28 (2.04 to $-0.53 ; p=0.001)$ and $-1.33(-2.53$ to $-0.13 ; p=0.030)$. The estimates are for a point change in the scholastic test scores, after adjustment for sex, left-hand motor function and social class. Statistically significant associations with mixed-handedness were only observed for the lowest third of right-hand motor function.

Conclusions: Measures involving poorer left-hand motor function may represent useful markers of reduced cognitive function possibly reflecting suboptimal hemispheric lateralisation. Crude measures of laterality such as reported non-right-handedness may be more useful for research when combined with measures of motor function.

\section{INTRODUCTION}

Non-right-handedness is linked with a raised risk of scholastic and language difficulties, as well as mental health or behavioural problems such as attention-deficit/hyperactivity disorder (ADHD), ${ }^{12}$ and suboptimal hemi-

\section{ARTICLE SUMMARY}

Article focus

- Some patterns of laterality and hand use can signal atypical brain development before birth relevant to problems with language development and scholastic performance. Measures of leftand right-hand control were investigated as markers of cognitive function and were combined with a crude measure of laterality in an attempt to improve its usefulness as a marker of underlying problems relevant to lateralisation and impaired scholastic performance.

Key messages

- Poorer results from tests of hand control, particularly for the left side, are associated with lower scholastic test scores.

- Combining crude measures of laterality with hand control test results may improve their usefulness in research to identify children with potentially suboptimal neurological development.

Strengths and limitations of this study

- The study benefited from use of a large cohort of children representative of the British general population.

- The study did not identify the neurological processes responsible, or their causes, only potential markers for use in research.

spheric lateralisation is one of the factors thought to explain these associations. ${ }^{3-5}$ Research using a longitudinal birth cohort study in Finland ${ }^{6}$ demonstrated that the most notable associations with impaired scholastic ability are among those who are mixedhanded (ambidextrous) rather than lefthanded. Unsophisticated measures such as reported right-handedness, left-handedness and mixed-handedness, as used in the Finnish study, ${ }^{6}$ are imprecise markers of subtle developmental deficits and may therefore be of limited use in research. This paper is concerned with examining simple measures of laterality and hand control including measures of motor function, which may signal developmental deficits relevant to scholastic ability.

Motor function is associated with ability in both reading and mathematics ${ }^{7-10}$ and thus 
a useful indicator of relevant general neurological function. We used a measure of motor function, involving tasks for the left and right hands. The aims of using the motor test scores were to identify children among whom non-right-handedness is a better indicator of poorer scholastic ability and also to examine whether the motor test results themselves provide more useful information than an unsophisticated classification of laterality (left-, right- and mixed-handed where no hand preference was specified).

A British general population-based birth cohort study ${ }^{11}$ provided information on laterality, and two tests of motor function for both left and right hand were administered by a doctor at age 11 years: time to pick up 20 matches and number of boxes ticked within a time limit. We chose to use the picking up matches test, as ticking boxes involves writing skills, which could be more influenced by cultural norms for hand preference, ${ }^{12}$ and therefore, we hypothesised potentially less precise as a less dominant hand may be used more, thus improving performance. For outcome measures of cognitive or scholastic ability, we used four tests conducted at age 11 years. The main analysis was stratified by level of righthand motor function (in equal thirds of the distribution). The right hand was chosen as it tends to be the dominant hand.

\section{METHODS}

\section{Research setting and study design}

A total of 10612 cohort members from The National Child Development Study (NCDS) ${ }^{11}$ were included in the analyses. NCDS is following everyone born between 3 and 9 March 1958 and living in Great Britain, with data collection sweeps at various ages. ${ }^{13}$ The study originally comprised approximately 17000 births, but the subsequent exclusion of Northern Ireland, death, emigration and other causes of attrition reduced the sample size, although the cohort has remained broadly representative of the target population. ${ }^{14}$

\section{Measures}

Laterality and hand control

When the children were aged 7 years, mothers were asked if they thought their child was right-handed, lefthanded, ambidextrous (mixed handed) or don't know. Local authority medical officers administered a series of functional assessments. The chosen test of motor function was undertaken at age 11 years and recorded the time in seconds that it took to pick up 20 matches (maximum $99 \mathrm{~s}$ ), separately for left and right hand, with a higher score indicating poorer performance.

\section{Scholastic ability}

Teachers administered tests of cognition and scholastic ability at school when the children were 11 years old. These tests were for verbal general ability (score range $0-40)$, non-verbal general ability $(0-40)$, reading comprehension (0-35) and mathematics (0-40). The tests were constructed specifically for use in NCDS by the National Foundation for Educational Research in England and Wales. ${ }^{11} 15$

\section{Other measures}

At age 11 years, local authority medical officers conducted a medical examination and record review, which identified children with a 'general motor handicap' with categories: 'none', 'condition present but no handicap', 'slight handicap', 'moderate handicap' or 'severe handicap'. Social class (Registrar General) based on the father's occupation was categorised as I, II, III non-manual, III manual, IV non-manual, IV manual, V, no father present and 'not assigned' (where there was insufficient information).

\section{Inclusion and exclusion criteria}

Information on laterality and the picking up matches test score was available for 11489 children. Of these, 37 reported uncertain laterality and were excluded. A further 129 were excluded due to missing data on parental social class. From among those remaining, 10657 completed at least one scholastic ability test, but 45 were excluded due to an observed or diagnosed condition or disability relevant to motor function. Data for 10612 children were available for the tests of verbal general ability, non-verbal general ability and reading comprehension. Data for 10608 children were available for the mathematics test.

\section{Statistical analysis}

Means and cross-tabulation describe the study population, and this analysis was stratified by laterality. The scores for picking up matches (the marker of motor control) for left and right hands were divided into equal thirds of their distributions.

Linear regression models used test scores as dependent variables: verbal general ability, non-verbal general ability, reading comprehension and mathematics. Analyses were externally stratified by right-hand motor function test thirds (separate analyses for each third). Further analysis combined the two highest right-hand motor function thirds to ensure that statistical significance in the lowest function third could not be explained by greater statistical power. Variables included in the analyses were laterality, left-hand motor test score (in thirds), sex and social class. The measures were modelled as series of binary dummy variables, first examined separately and then with mutual simultaneous adjustment.

Interaction testing assessed whether stratification by right-hand motor function modified the associations of laterality with the tests of scholastic ability. Interaction terms (and main effects) were included in non-stratified linear regression models with the measures of scholastic ability as dependent variables. Similar interaction testing examined the combination of left- and right-hand motor 
function (in thirds of their distributions due to nonlinearity). PASW V.18 software was used.

\section{Ethics}

Specific ethical permission was not required for this secondary analysis of anonymised data.

\section{RESULTS}

Table 1 shows the population characteristics, presented in separate columns for right-, left- and mixed-handedness. Non-right-handedness was associated with somewhat lower average test scores for general ability (both verbal and non-verbal), reading comprehension and mathematics, with little difference between left- and mixed-handedness.

As expected, left-handed cohort members were more often in the highest third for the left-hand motor function test and the lowest third for the right-hand test. Boys predominate among the left- or mixed-handed. Nonright-handedness is somewhat associated with lower parental social class.

In tables 2-5, results are stratified into thirds of the right-hand motor function test (picking up matches), where the top section of the tables is for those with the poorest performance. The number of subjects in each stratum and laterality group can be ascertained from table 1 .

\section{Verbal general ability}

Among those in the lowest right-hand motor function group, left- and particularly mixed-handedness, compared with right-handedness, are statistically significantly and independently associated with lower verbal general ability scores (table 2). Statistically significant associations for laterality were not observed in the two higher thirds for right-hand motor function. Interaction testing provided evidence of effect modification by right-hand motor function for mixed-handedness $(\mathrm{p}=0.039)$, but not left-handedness $(\mathrm{p}=0.980)$. Lower left-hand motor function test scores were statistically significantly associated with lower verbal general ability scores in the lowest right-hand stratum, independent of the potential confounding factors (although interaction testing was not significant). A borderline statistically significantly reduced score for low left-hand function was also observed in the highest right hand function stratum.

\section{Non-verbal general ability}

Among those in the lowest right-hand motor function stratum, lower non-verbal general ability scores were

Table 1 Characteristics of the study population divided by hand laterality

\begin{tabular}{|c|c|c|c|}
\hline & \multicolumn{3}{|c|}{ Mean value (SD) or $n(\%)$, by hand laterality } \\
\hline & Right & Left & Mixed \\
\hline \multicolumn{4}{|l|}{ Mean test score } \\
\hline Verbal general ability & 22.8 (SD 9.2) & 21.6 (SD 9.5) & 21.4 (SD 9.2) \\
\hline Non-verbal general ability & $21.4(\mathrm{SD} 7.4)$ & 20.6 (SD 7.6) & 20.7 (SD 7.6) \\
\hline Reading comprehension & 16.4 (SD 6.2) & 15.9 (SD 6.4) & $16.0(\mathrm{SD} 6.5)$ \\
\hline Mathematics & 17.4 (SD 10.3) & 16.6 (SD 10.3) & $16.3(\mathrm{SD} 10.3)$ \\
\hline \multicolumn{4}{|l|}{ Right-hand motor score } \\
\hline Lowest third ${ }^{*}$ & 2967 (33.4) & $457(41.7)$ & $272(36.9)$ \\
\hline Middle third & $2921(32.8)$ & $331(30.2)$ & $235(31.9)$ \\
\hline Highest third & $3008(33.8)$ & $307(28.0)$ & $230(31.2)$ \\
\hline \multicolumn{4}{|l|}{ Left-hand motor score } \\
\hline Lowest third* & $2976(33.5)$ & $312(28.5)$ & $238(32.3)$ \\
\hline Middle third & $3192(35.9)$ & $391(35.7)$ & $260(35.3)$ \\
\hline Highest third & $2728(30.7)$ & $392(35.8)$ & $239(32.4)$ \\
\hline \multicolumn{4}{|l|}{ Sex } \\
\hline Male & $4391(49.4)$ & $626(57.2)$ & $446(60.5)$ \\
\hline Female & $4505(50.6)$ & 469 (42.8) & $291(39.5)$ \\
\hline \multicolumn{4}{|c|}{ Fathers' social class (Registrar General's) } \\
\hline I & $448(5.0)$ & $52(4.7)$ & $39(5.3)$ \\
\hline II & $1313(14.8)$ & $150(13.7)$ & $83(11.3)$ \\
\hline III non-manual & $888(10.0)$ & $91(8.3)$ & $70(9.5)$ \\
\hline III manual & 3853 (43.3) & $513(46.8)$ & $328(44.5)$ \\
\hline IV non-manual & $173(1.9)$ & $11(1.0)$ & $14(1.9)$ \\
\hline IV manual & $1362(15.3)$ & $161(14.7)$ & $128(17.4)$ \\
\hline $\mathrm{V}$ & $541(6.1)$ & $69(6.3)$ & $43(5.8)$ \\
\hline Information missing & $83(0.9)$ & $25(2.3)$ & $8(1.1)$ \\
\hline No male head & $235(2.6)$ & $23(2.1)$ & 24 (3.3) \\
\hline Total (row \%) & $8896(82.9)$ & 1095 (10.2) & $737(6.9)$ \\
\hline
\end{tabular}

*The lowest third of the motor function tests indicates poorest performance (longest time to pick up 20 matches). 
Table 2 Verbal general ability test and laterality, stratified by right-hand motor score

\begin{tabular}{|c|c|c|c|c|c|}
\hline & $\begin{array}{l}\text { Test score } \\
\text { Mean value (SD) }\end{array}$ & \multicolumn{2}{|l|}{ Unadjusted } & \multicolumn{2}{|l|}{ Adjusted* } \\
\hline \multicolumn{6}{|c|}{ Lowest third $\dagger$ (right hand) } \\
\hline Right & $21.85(9.28)$ & Reference & & Reference & \\
\hline Left & $20.37(9.77$ & $-1.48(-2.40$ to -0.56$)$ & 0.002 & $-1.51(-2.38$ to -0.63$)$ & 0.001 \\
\hline Mixed & $19.77(9.14)$ & $-2.08(-3.23$ to -0.92$)$ & $<0.001$ & $-1.90(-3.01$ to -0.80$)$ & 0.001 \\
\hline Lowest third $\dagger$ & $20.97(9.45)$ & $-1.46(-2.77$ to -0.15$)$ & 0.029 & $-1.39(-2.64$ to -0.15$)$ & 0.028 \\
\hline Middle third & $22.52(9.19)$ & $0.09(-1.28$ to 1.46$)$ & 0.901 & $0.02(-1.29$ to 1.32$)$ & 0.981 \\
\hline Highest third & $22.43(8.51)$ & Reference & & Reference & \\
\hline \multicolumn{6}{|c|}{ Middle third (right hand) } \\
\hline \multicolumn{6}{|c|}{ Laterality } \\
\hline Right & $22.84(9.05)$ & Reference & & Reference & \\
\hline \multicolumn{6}{|c|}{ Left-hand motor score } \\
\hline Middle third & $23.01(9.18)$ & $0.15(-0.62$ to 0.92$)$ & 0.707 & $0.27(-0.47$ to 1.01$)$ & 0.477 \\
\hline Highest third & $22.86(9.03)$ & Reference & & Reference & \\
\hline \multicolumn{6}{|c|}{ Highest third (right hand) } \\
\hline \multicolumn{6}{|c|}{ Laterality } \\
\hline Right & $23.77(9.05)$ & Reference & & Reference & \\
\hline Left & $22.85(9.08)$ & $-0.91(-1.98$ to 0.15$)$ & 0.092 & $-0.92(-1.94$ to 0.09$)$ & 0.074 \\
\hline Mixed & $22.62(8.98)$ & $-1.14(-2.36$ to 0.07$)$ & 0.065 & $-0.74(-1.89$ to 0.42$)$ & 0.210 \\
\hline \multicolumn{6}{|c|}{ Left-hand motor score } \\
\hline Lowest third $\dagger$ & $22.50(8.83)$ & $-1.36(-2.72$ to 0.00$)$ & 0.050 & $-1.33(-2.62$ to 0.05$)$ & 0.042 \\
\hline Middle third & $23.22(8.91)$ & $-0.64(-1.31$ to 0.04$)$ & 0.064 & $-0.45(-1.09$ to 0.19$)$ & 0.171 \\
\hline Highest third & $23.86(9.12)$ & Reference & & Reference & \\
\hline
\end{tabular}

statistically significantly and independently associated with left- and particularly mixed-handedness compared with right-handedness (table 3). Non-right-handedness was not statistically significantly associated with the verbal general ability scores in the two higher righthand motor function strata. Interaction testing provided evidence of effect modification by right-hand motor function for mixed-handedness $(p=0.012)$, but not left-handedness $(\mathrm{p}=0.786)$.

Lower left-hand motor function test scores were statistically significantly associated with lower verbal general ability scores in the lowest right-hand performance third, independent of the potential confounding factors. Interaction testing suggests effect modification for the combination of low left-hand function with low right function $(\mathrm{p}=0.007)$.

\section{Reading comprehension}

Among those in the lowest right-hand motor function stratum, lower reading comprehension scores were associated with mixed-handedness compared with righthandedness (table 4). After adjustment, the associations with both left- and mixed-handedness were statistically significant. Non-right-handedness was not statistically significantly associated with the reading comprehension scores in the two higher right-hand performance strata.
Interaction testing provided evidence of effect modification by right-hand motor function for mixed-handedness $(p<0.001)$, but not left-handedness $(p=0.598)$.

Lower left-hand motor function test scores were statistically significantly associated with lower reading comprehension scores in the lowest and highest right-hand performance thirds, independent of the potential confounding factors (although interaction testing was not statistically significant).

\section{Mathematics}

Among those in the lowest right-hand motor function stratum, lower test scores were associated with left- and particularly mixed-handedness compared with righthandedness (table 5).

These associations were statistically significant and independent of the potential confounding factors. Nonright-handedness was not statistically significantly associated with the mathematics test scores in the two higher right-hand performance strata. Interaction testing did not provide strong evidence of effect modification by right-hand motor function for mixed-handedness $(\mathrm{p}=0.195)$ or left-handedness $(\mathrm{p}=0.810)$.

Lower left-hand motor function test scores were statistically significantly associated with lower mathematics test scores in the lowest and highest right-hand 
Table 3 Non-verbal general ability test and laterality, stratified by right-hand motor score

\begin{tabular}{|c|c|c|c|c|c|}
\hline & \multirow{2}{*}{$\begin{array}{l}\text { Test score } \\
\text { Mean value (SD) }\end{array}$} & \multicolumn{2}{|l|}{ Unadjusted } & \multicolumn{2}{|l|}{ Adjusted* } \\
\hline & & Coefficient (95\% CI) & p Value & Coefficient (95\% Cl) & p Value \\
\hline \multicolumn{6}{|c|}{ Lowest third $†$ (right hand) } \\
\hline Right & $20.69(7.57)$ & Reference & & Reference & \\
\hline Left & $19.74(7.88)$ & $-0.95(-1.70$ to -0.20$)$ & 0.013 & $-1.05(-1.77$ to -0.34$)$ & 0.004 \\
\hline Mixed & $19.42(7.60)$ & $-1.27(-2.22$ to -0.33$)$ & 0.008 & $-1.25(-2.15$ to -0.35$)$ & 0.007 \\
\hline Lowest third $\dagger$ & $20.01(7.76)$ & $-1.13(-2.19$ to -0.06$)$ & 0.038 & $-0.99(-2.01$ to 0.03$)$ & 0.056 \\
\hline Middle third & $21.38(7.34)$ & $0.25(-0.87$ to 1.36$)$ & 0.663 & $0.27(-0.79$ to 1.33$)$ & 0.620 \\
\hline Highest third & $21.14(7.01)$ & Reference & & Reference & \\
\hline \multicolumn{6}{|c|}{ Middle third (right hand) } \\
\hline \multicolumn{6}{|c|}{ Laterality } \\
\hline Right & $21.40(7.33)$ & Reference & & Reference & \\
\hline Middle third & $21.48(7.47)$ & $0.18(-0.45$ to 0.80$)$ & 0.577 & $0.30(-0.31$ to 0.90$)$ & 0.335 \\
\hline Highest third & $21.30(7.45)$ & Reference & & Reference & \\
\hline \multicolumn{6}{|c|}{ Highest third (right hand) } \\
\hline \multicolumn{6}{|c|}{ Laterality } \\
\hline Right & $22.24(7.24)$ & Reference & & Reference & \\
\hline Left & $21.55(7.13)$ & $-0.69(-1.54$ to 0.16$)$ & 0.111 & $-0.79(-1.60$ to 0.03$)$ & 0.058 \\
\hline Mixed & $21.77(7.36)$ & $-0.48(-1.45$ to 0.49$)$ & 0.335 & $-0.33(-1.26$ to 0.59$)$ & 0.480 \\
\hline \multicolumn{6}{|c|}{ Left-hand motor score } \\
\hline Lowest third $\dagger$ & $21.64(7.17)$ & $-0.67(-1.76$ to 0.41$)$ & 0.224 & $-0.64(-1.68$ to 0.39$)$ & 0.220 \\
\hline Middle third & $21.87(7.20)$ & $-0.44(-0.98$ to 0.10$)$ & 0.106 & $-0.27(-0.78$ to 0.24$)$ & 0.301 \\
\hline Highest third & $22.31(7.26)$ & Reference & & Reference & \\
\hline
\end{tabular}

performance thirds, independent of the potential confounding factors. Interaction testing did not identify effect modification $(\mathrm{p}>0.05)$.

In further analyses, the two higher right-hand motor function score thirds were combined to ensure that the statistical significance of associations of laterality with the scholastic test scores in the lowest right-hand motor function stratum were not due to greater statistical power. Neither left- nor mixed-handedness is statistically significantly associated with any of the scholastic tests in the combined top two thirds for right-hand motor function (data not shown). There were no notable gradients in the association of laterality with the scholastic test scores across the two higher right-hand motor function strata. Although the average scholastic test scores tended to be lower among those who were mixedhanded than for left-handedness, no statistically significant differences were observed when mixed-handedness was compared with left-handedness.

\section{Non-stratified analysis}

Table 6 shows associations with each of the four scholastic tests for laterality, right-hand motor function and left-hand motor function test scores. Right-handedness and the highest third of the motor function tests were used as reference categories. In the adjusted models, non-right-handedness was associated with statistically significantly poorer scholastic ability, except for the reading comprehension test. It is notable that cohort members with left-hand motor scores in lowest third had lower average scholastic test scores than those with parentally reported non-right-handed laterality. Poorer left-hand function was associated with lower average scholastic scores than poorer right-hand function, except for non-verbal general ability where low righthand function was associated with somewhat lower scores.

The online appendix presents the results of further analyses showing similar associations, where the motor function test involved ticking boxes rather than picking up matches.

\section{DISCUSSION}

Although the a priori hypothesis for this study involved the combination of lack of reported hand preference (described as 'mixed-handedness') with a measure of right-hand motor function, the measures of left- and right-hand motor function themselves may have produced more informative results. Poorer motor function in both hands, but particularly the left, was 
Table 4 Reading comprehension test and laterality, stratified by right-hand motor score

\begin{tabular}{|c|c|c|c|c|c|}
\hline & \multirow{2}{*}{$\begin{array}{l}\text { Test score } \\
\text { Mean value (SD) }\end{array}$} & \multicolumn{2}{|l|}{ Unadjusted } & \multicolumn{2}{|l|}{ Adjusted* $^{\star}$} \\
\hline & & Coefficient (95\% Cl) & p Value & Coefficient (95\% Cl) & p Value \\
\hline \multicolumn{6}{|c|}{ Lowest third $\dagger$ (right hand) } \\
\hline \multicolumn{6}{|c|}{ Laterality } \\
\hline Right & $15.91(6.42)$ & Reference & & Reference & \\
\hline Left & $15.34(6.74)$ & $-0.57(-1.21$ to 0.07$)$ & 0.081 & $-0.64(-1.24$ to -0.04$)$ & 0.036 \\
\hline Mixed & $14.52(6.46)$ & $-1.39(-2.19$ to -0.58$)$ & 0.001 & $-1.28(-2.04$ to -0.53$)$ & 0.001 \\
\hline \multicolumn{6}{|c|}{ Left-hand motor score } \\
\hline Lowest third $\dagger$ & $15.40(6.59)$ & $-1.19(-2.10$ to -0.29$)$ & 0.010 & $-1.05(-1.91$ to -0.20$)$ & 0.016 \\
\hline Middle third & $16.32(6.27)$ & $-0.27(-1.22$ to 0.68$)$ & 0.581 & $-0.26(-1.15$ to 0.64$)$ & 0.571 \\
\hline Highest third & $16.59(5.91)$ & Reference & & Reference & \\
\hline \multicolumn{6}{|c|}{ Middle third (right hand) } \\
\hline \multicolumn{6}{|c|}{ Laterality } \\
\hline Right & $16.36(6.06)$ & Reference & & Reference & \\
\hline Left & $16.02(6.07)$ & $-0.34(-1.03$ to 0.36$)$ & 0.341 & $-0.10(-0.76$ to 0.56$)$ & 0.763 \\
\hline Mixed & $16.49(6.53)$ & $0.14(-0.67$ to 0.95$)$ & 0.737 & $0.32(-0.45$ to 1.09$)$ & 0.414 \\
\hline \multicolumn{6}{|c|}{ Left-hand motor score } \\
\hline Lowest third $\dagger$ & $16.00(5.98)$ & $-0.48(-1.06$ to 0.10$)$ & 0.106 & $-0.28(-0.83$ to 0.27$)$ & 0.324 \\
\hline Middle third & $16.45(6.20)$ & $-0.03(-0.55$ to 0.49$)$ & 0.912 & $0.10(-0.39$ to 0.60$)$ & 0.677 \\
\hline Highest third & $16.48(5.99)$ & Reference & & Reference & \\
\hline \multicolumn{6}{|c|}{ Highest third (right hand) } \\
\hline \multicolumn{6}{|c|}{ Laterality } \\
\hline Right & $16.86(5.94)$ & Reference & & Reference & \\
\hline Left & $16.73(6.20)$ & $-0.12(-0.83$ to 0.58$)$ & 0.732 & $-0.21(-0.87$ to 0.46$)$ & 0.539 \\
\hline Mixed & $17.11(6.13)$ & $0.25(-0.55$ to 1.05$)$ & 0.536 & $0.35(-0.40$ to 1.11$)$ & 0.360 \\
\hline \multicolumn{6}{|c|}{ Left-hand motor score } \\
\hline Lowest third $\dagger$ & $16.07(5.85)$ & $-0.95(-1.84$ to -0.05$)$ & 0.038 & $-0.90(-1.75$ to -0.06$)$ & 0.036 \\
\hline Middle third & $16.64(5.99)$ & $-0.37(-0.81$ to 0.08$)$ & 0.105 & $-0.20(-0.62$ to 0.22$)$ & 0.353 \\
\hline Highest third & $17.01(5.98)$ & Reference & & Reference & \\
\hline
\end{tabular}

*Adjusted for laterality, left-hand motor score, sex and parental social class.

†The lowest third of the motor function tests indicates poorest performance (longest time to pick up 20 matches).

associated with poorer scholastic ability. The combination of poor left-hand motor function with either low or high right-hand function was associated with lower average test scores. Non-right-handedness alone was not notably associated with poorer scholastic ability; only the combination of non-right-handedness and lower right hand motor function (the lowest third) was consistently associated with poor scholastic ability. Interaction testing indicated effect modification for the specific combination of no reported hand preference and poorer motor performance.

A previous study demonstrated an association between 'mixed-handedness' (lack of reported hand preference) and poorer scholastic performance, where laterality was reported by parents using a single-item question. ${ }^{6}$ For comparability, we also used parent-reported laterality but combined this with left- and right-hand motor function tests. Associations of motor function ${ }^{16-18}$ and laterality $^{6-10}$ with intelligence and scholastic ability have been demonstrated previously, but this combination of motor function with this measure of handedness in the general population is more novel. Studies of laterality often use a series of questions for more precise classification, ${ }^{19-21}$ rather than the single question used by this study which limits accuracy significantly. A more elabo- rate approach also allows grading of strength of left- or right-handedness. A lack of reported hand preference may reflect uncertainty about laterality, ${ }^{19}$ so a more precise instrument should reduce the misclassification that is likely to have existed in our study. For this reason, our 'mixed-handed' group may be heterogeneous, and the results using parent-reported handedness should be interpreted with caution. Despite this imprecision, interpretability of the results may have been increased by our use of more objective left- and right-hand motor function measures. Although imprecise, the laterality measure used here can be compared with other studies that have used a similar simple measure. Nonright-handedness among the lowest right-hand motor function group may help to identify a small subgrou$\mathrm{p}$ at greater risk of having suboptimal hemispheric lateralisation.

Motor function is associated with cognitive ability, ${ }^{7-10}$ and a striking feature of our findings is the magnitude of the association of poor left hand motor function with worse scholastic test scores. Interestingly, the combination of low left-hand function with either low or high right-hand function was associated with lower scholastic test scores. This is consistent with Marian Annett's right shift theory of handedness and cerebral dominance, 
Table 5 Mathematics test and laterality, stratified by right-hand motor score

\begin{tabular}{|c|c|c|c|c|c|}
\hline & $\begin{array}{l}\text { Test score } \\
\text { Mean value (SD) }\end{array}$ & \multicolumn{2}{|l|}{ Unadjusted } & \multicolumn{2}{|l|}{ Adjusted* } \\
\hline \multicolumn{6}{|c|}{ Lowest third $\dagger$ (right hand) } \\
\hline Right & $16.35(10.28)$ & Reference & & Reference & \\
\hline Left & $15.42(10.33)$ & $-0.93(-1.95$ to 0.08$)$ & 0.071 & $-1.12(-2.07$ to -0.17$)$ & 0.021 \\
\hline Mixed & $14.96(10.29)$ & $-1.39(-2.67$ to -0.11$)$ & 0.034 & $-1.33(-2.53$ to -0.13$)$ & 0.030 \\
\hline Lowest third $\dagger$ & $15.57(10.30)$ & $-1.56(-3.00$ to -0.12$)$ & 0.034 & $-1.26(-2.62$ to 0.09$)$ & 0.067 \\
\hline Middle third & $17.17(10.35)$ & $0.05(-1.46$ to 1.56$)$ & 0.951 & $0.15(-1.27$ to 1.57$)$ & 0.834 \\
\hline Highest third & $17.13(9.50)$ & Reference & & Reference & \\
\hline \multicolumn{6}{|c|}{ Middle third (right hand) } \\
\hline \multicolumn{6}{|c|}{ Laterality } \\
\hline Right & $17.47(10.14)$ & Reference & & Reference & \\
\hline Middle third & $17.63(10.24)$ & $-0.05(-0.91$ to 0.81$)$ & 0.912 & $0.14(-0.68$ to 0.96$)$ & 0.743 \\
\hline Highest third & $17.68(10.38)$ & Reference & & Reference & \\
\hline \multicolumn{6}{|c|}{ Highest third (right hand) } \\
\hline \multicolumn{6}{|c|}{ Laterality } \\
\hline Right & $18.36(10.28)$ & Reference & & Reference & \\
\hline Left & $17.79(9.94)$ & $-0.57(-1.78$ to 0.63$)$ & 0.352 & $-0.77(-1.91$ to 0.36$)$ & 0.180 \\
\hline Mixed & $17.65(10.29)$ & $-0.71(-2.09$ to 0.66$)$ & 0.310 & $-0.61(-1.90$ to 0.68$)$ & 0.352 \\
\hline \multicolumn{6}{|c|}{ Left-hand motor score } \\
\hline Lowest third $\dagger$ & $16.64(10.51)$ & $-1.93(-3.47$ to -0.39$)$ & 0.014 & $-1.73(-3.27$ to -0.40$)$ & 0.012 \\
\hline Middle third & $17.84(10.10)$ & $-0.73(-1.49$ to 0.03$)$ & 0.060 & $-0.45(-1.16$ to 0.27$)$ & 0.221 \\
\hline Highest third & $18.57(10.28)$ & Reference & & Reference & \\
\hline
\end{tabular}

where hypothetical genetic factors produce a continuum of hemispheric asymmetry. ${ }^{22}$ A lack of asymmetry may be detrimental for some aspects of hemispheric specialisation, but excessive asymmetry (as signalled by high rightand low left-hand motor function) may also limit some functions relevant to cognition and behaviour. ${ }^{22}$ Strong right-handedness has been linked with poorer cognitive function, including for episodic memory. ${ }^{23-25}$

In addition to stratifying by right hand motor function and adjusting for left hand motor function, we adjusted for several other measures to ensure that the results were not due to confounding. We adjusted for sex as it is associated with laterality, motor control and scholastic ability. $^{26}$ We also included parental social class to improve precision, as there are social influences on learning and problem solving. ${ }^{28}$ To ensure that the results are not influenced by a small group of children with disabilities, children with any diagnosed motor disabilities were excluded from the analysis. We did not adjust for developmental factors, as the study was designed to examine measures of handedness, rather than identify causes.

While this study cannot identify the neurological mechanisms underlying associations between laterality or hand control and scholastic performance, suboptimal hemispheric lateralisation is one possible component of the explanation. Task specialisation between the left and right hemispheres can be associated with cerebral asymmetry in anatomy, neurotransmitter expression and inter-hemispheric signalling. ${ }^{29-31}$ A high degree of lateralisation in function may result in, or be influenced by, higher level cognitive function. ${ }^{32}$ Abnormalities in cerebral asymmetry and inter-hemispheric signalling have been associated with developmental and behavioural problems such as $\mathrm{ADHD},{ }^{4}$ so related difficulties may help explain our findings. Boys appear to be particularly susceptible to in utero exposures relevant to suboptimal lateralisation, as premature boys are at greater risk of non-right-handedness and behavioural disorders like ADHD. ${ }^{33}$ A consistent finding is that more of the boys in this study were non-right-handed. Functional cortical asymmetry can vary with age, ${ }^{30}$ indicating that later life exposures may influence whether suboptimal lateralisation persists.

Potential limitations of this study include the imprecise laterality measure reported by mothers, particularly as the 'mixed-handed' category reflects no reported hand preference rather than a more structured assessment of whether an individual is ambidextrous. Division of the motor function scores into equal thirds may not be optimal but chosen on an a priori basis to demonstrate a constant pattern with the minimum number of 
Table 6 Non-stratified analysis of associations with each of the four scholastic tests, for laterality and the hand motor function tests

\begin{tabular}{|c|c|c|c|c|c|}
\hline & \multirow{2}{*}{$\begin{array}{l}\text { Test score } \\
\text { Mean value (SD) }\end{array}$} & \multicolumn{2}{|l|}{ Unadjusted } & \multicolumn{2}{|l|}{ Adjusted* } \\
\hline & & Coefficient $(95 \% \mathrm{Cl})$ & p Value & Coefficient $(95 \% \mathrm{Cl})$ & p Value \\
\hline \multicolumn{6}{|l|}{ Verbal score } \\
\hline \multicolumn{6}{|l|}{ Laterality $\dagger$} \\
\hline Left & $21.63(9.46)$ & $-1.19(-1.77$ to -0.62$)$ & $<0.001$ & $-0.91(-1.46$ to -0.36$)$ & 0.001 \\
\hline Mixed & 21.39 (9.19) & $-1.43(-2.12$ to -0.74$)$ & $<0.001$ & $-1.03(-1.69$ to -0.38$)$ & 0.002 \\
\hline \multicolumn{6}{|c|}{ Left-hand motor score $\neq$} \\
\hline Lowest third & $21.36(9.29)$ & $-2.19(-2.62$ to -1.75$)$ & $<0.001$ & $-1.21(-1.73$ to -0.68$)$ & $<0.001$ \\
\hline Middle third & $22.92(9.11)$ & $-0.62(-1.04$ to -0.19$)$ & 0.004 & $-0.12(-0.56$ to 0.33$)$ & 0.610 \\
\hline \multicolumn{6}{|c|}{ Right-hand motor score $\neq$} \\
\hline Lowest third & $21.51(9.35)$ & $-2.10(-2.52$ to -1.68$)$ & $<0.001$ & $-0.84(-1.35$ to -0.32$)$ & 0.001 \\
\hline Middle third & $22.73(9.08)$ & $-0.88(-1.31$ to -0.46$)$ & $<0.001$ & $-0.30(-0.75$ to 0.15$)$ & 0.192 \\
\hline \multicolumn{6}{|l|}{ Non-verbal score } \\
\hline \multicolumn{6}{|l|}{ Laterality $\dagger$} \\
\hline Left & $20.61(7.61)$ & $-0.84(-1.31$ to -0.38$)$ & $<0.001$ & $-0.70(-1.15$ to -0.25$)$ & 0.002 \\
\hline Mixed & 20.67 (7.62) & $-0.78(-1.34$ to -0.22$)$ & 0.006 & $-0.60(-1.13$ to -0.07$)$ & 0.027 \\
\hline \multicolumn{6}{|c|}{ Left-hand motor score $\neq$} \\
\hline Lowest third & $20.39(7.58)$ & $-1.62(-1.97$ to -1.27$)$ & $<0.001$ & $-0.72(-1.14$ to -0.29$)$ & 0.001 \\
\hline Middle third & $21.55(7.37)$ & $-0.46(-0.80$ to -0.11$)$ & 0.009 & $0.05(-0.32$ to 0.41$)$ & 0.799 \\
\hline \multicolumn{6}{|c|}{ Right-hand motor score $\neq$} \\
\hline Lowest third & $20.48(7.62)$ & $-1.67(-2.01$ to -1.33$)$ & $<0.001$ & $-0.91(-1.33$ to -0.49$)$ & $<0.001$ \\
\hline Middle third & $21.33(7.38)$ & $-0.82(-1.17$ to -0.47$)$ & $<0.001$ & $-0.47(-0.84$ to -0.10$)$ & 0.012 \\
\hline \multicolumn{6}{|c|}{ Reading ability score } \\
\hline \multicolumn{6}{|c|}{ Laterality $\dagger$} \\
\hline Left & $15.94(6.42)$ & $-0.44(-0.83$ to -0.05$)$ & 0.027 & $-0.33(-0.70$ to 0.04$)$ & 0.078 \\
\hline Mixed & $15.96(6.47)$ & $-0.42(-0.88$ to 0.05$)$ & 0.079 & $-0.27(-0.71$ to -0.16$)$ & 0.221 \\
\hline \multicolumn{6}{|c|}{ Left-hand motor score $\neq$} \\
\hline Lowest third & $15.59(6.40)$ & $-1.27(-1.56$ to -0.98$)$ & $<0.001$ & $-0.70(-1.06$ to -0.35$)$ & $<0.001$ \\
\hline Middle third & $16.46(6.17)$ & $-0.40(-0.69$ to -0.12$)$ & 0.006 & $-0.09(-0.39$ to 0.21$)$ & 0.544 \\
\hline \multicolumn{6}{|c|}{ Right-hand motor score $\ddagger$} \\
\hline Lowest third & $15.74(6.48)$ & $-1.12(-1.41$ to -0.84$)$ & $<0.001$ & $-0.41(-0.76$ to -0.07$)$ & 0.019 \\
\hline Middle third & $16.33(6.10)$ & $-0.53(-0.82$ to -0.24$)$ & $<0.001$ & $-0.18(-0.48$ to 0.13$)$ & 0.256 \\
\hline \multicolumn{6}{|c|}{ Mathematics test score } \\
\hline \multicolumn{6}{|c|}{ Laterality $\dagger$} \\
\hline Left & $16.56(10.33)$ & $-0.83(-1.48$ to -0.19$)$ & 0.011 & $-0.70(-1.31$ to -0.10$)$ & 0.023 \\
\hline Mixed & $16.33(10.31)$ & $-1.06(-1.83$ to -0.29$)$ & 0.007 & $-0.87(-1.60$ to -0.15$)$ & 0.018 \\
\hline \multicolumn{6}{|c|}{ Left-hand motor score $\neq$} \\
\hline Lowest third & $15.91(10.20)$ & $-2.36(-2.85$ to -1.88$)$ & $<0.001$ & $-1.32(-1.90$ to -0.73$)$ & $<0.001$ \\
\hline Middle third & $17.55(10.24)$ & $-0.72(-1.19$ to -0.25$)$ & 0.003 & $-0.17(-0.67$ to 0.32$)$ & 0.499 \\
\hline \multicolumn{6}{|c|}{ Right-hand motor score $\neq$} \\
\hline Lowest third & $16.13(10.30)$ & $-2.13(-2.60$ to -1.66$)$ & $<0.001$ & $-0.88(-1.45$ to -0.32$)$ & 0.002 \\
\hline Middle third & $17.37(10.18)$ & $-0.90(-1.38$ to -0.42$)$ & $<0.001$ & $-0.28(-0.78$ to 0.22$)$ & 0.275 \\
\hline
\end{tabular}

groups. To ensure that differences in statistical power did not account for the findings, the two higher function thirds were combined and statistical significant association for mixed handedness were still only observed in the lowest function third. A limitation of the stratified design is that it could underestimate the overall magnitude of associations with scholastic test scores. The cohort remained largely representative of the general population, but loss of the most disadvantaged children $^{35}$ may have limited participation of some children with the poorest scholastic performance. The tests used here cannot identify causes or underlying mechanisms and these may be heterogeneous.

\section{CONCLUSIONS}

Simple objective tests of left- and right-hand motor function may be used to produce more useful markers of neurological characteristics relevant to scholastic performance than crude reports of left-handedness, right-handedness or where no hand preference is reported. If a crude measure of laterality is all that is available, combining it with a measure of objective motor 
function may improve its utility. The notably worse scholastic scores associated with poor left-hand function suggest that this may be a useful measure alone or in combination with others.

Contributors Dr TB was involved in drafting the manuscript and developing the analytic strategy. Mr $\mathrm{OB}$ was responsible for conducting the statistical analysis and produced the tables. Dr WO provided input on aspects of neurodevelopment. Professor SM devised the hypothesis and study design and was involved in drafting the manuscript. All the authors contributed to critical revision of the manuscript.

Funding This study received funding from the Örebro County Council Research Committee, Sweden, and from Economic and Social Research Council grant RES 596-28-0001 to the International Centre for Life Course Studies.

Competing interests None.

Patient consent Obtained.

Provenance and peer review Not commissioned; externally peer reviewed.

Data sharing statement All data used for this research were from the National Child development Study, available through the UK Data Archive (http://www. data-archive.ac.uk/)

\section{REFERENCES}

1. Rodriguez A, Jarvelin MR, Obel C, et al. Do inattention and hyperactivity symptoms equal scholastic impairment? Evidence from three European cohorts. BMC Public Health 2007:7:327.

2. Rodriguez A, Waldenstrom U. Fetal origins of child non-righthandedness and mental health. J Child Psychol Psychiatry 2008:49:967-76.

3. Leonard C, Eckert M. Assymmetry and dyslexia. Dev Neuropsychol 2008;33:663-81.

4. Valera EM, Farone SV, Murray KE, et al. Meta-analysis of structural imaging findings in attention-deficit/hyperactivity disorder. Biol Psychiatry 2007;61:1361-9.

5. Roessner V, Banaschewski $\mathrm{T}$, Uebel $\mathrm{H}$, et al. Neuronal network models of ADHD-lateralization with respect to interhemispheric connectivity reconsidered. Eur Child Adolesc Psychiatry 2004;13 (Suppl 1):PI71-9.

6. Rodriguez A, Kaakinen M, Moilanen I, et al. Mixed-handedness is linked to mental health problems in children and adolescents. Pediatrics 2010;125:e340-8.

7. Crow TJ, Crow LR, Dine DJ, et al. Relative hand skill predicts academic ability: global deficits at the point of hemispheric indecision. Neuropsychologia 1998;36:1275-82.

8. Leask SJ, Crow TJ. Word acquisition reflects lateralization of hand skill. Trends Cogn Sci 2001;5:513-16.

9. Leask SJ, Crow TJ. A single optimum degree of hemispheric specialisation in two tasks, in two UK national birth cohorts. Brain Cogn 2006;62:221-7.

10. Cheyne CP, Roberts N, Crow TJ, et al. The effect of handedness on academic ability: a multivariate linear mixed model approach. Laterality 2010;15:451-64.

11. Centre for longitudinal studies. National child development study [Internet] Guide to data set 2005. 2006. http://www.cls.ioe.ac.uk/ Default.aspx (accessed 7 Mar 2011).

12. Salmaso D, Longoni AM. Problems in the assessment of hand preference. Cortex 1985;21:533-49.

13. Ferri E. Life at 33: The Fifth Follow-up of the National Child Development Study. London: National Children's: Bureau, 1993.
14. Power C, Elliot J. Cohort profile: 1958 British birth cohort (national child development study). Int J Epidemiol 2006;35:34-41.

15. Douglas JWB. The Home and the School: The Study of Ability and Attainment in the Primary School. London: MacGibbon \& Kee, 1964

16. Tieman BL, Palisano RJ, Sutlive AC, et al. Assessment of motor development and function in preschool children. Profiles and cognitive predictors of motor functions among early school-age children with mild intellectual disabilities. Ment Retard Dev Disabil Res Rev 2005;11:189-96.

17. Wuang YP, Wang $\mathrm{CC}$, Huang $\mathrm{MH}$, et al. Profiles and cognitive predictors of motor functions among early school-age children with mild intellectual disabilities. J Intellect Disabil Res 2008;52:1048-60.

18. Bluechardt MH, Wiener J, Shephard RJ. Exercise programmes in the treatment of children with learning disabilities. Sports Med 1995;19:55-72.

19. Raczkowski D, Kalat JW, Nebes R. Reliability and validity of some handedness questionnaire items. Neuropsychologia 1974;12:43-7.

20. Lyle KB, McCabe DP, Roediger HL. Handedness is related to memory via hemispheric interaction: evidence from paired associate recall and source memory tasks. Neurpsychology 2008;22:523-30.

21. Oldfield RC. The assessment and analysis of handedness: the Edinburgh inventory. Neuropsychologia 1971;9:97-113.

22. Annett M. Handedness and cerebral dominance: The right shift theory. J Neuropsychiatry Clin Neurosci 1998;10:459-69.

23. Christman S, Propper R. An interhemispheric basis for episodic memory: effects of handedness and bilateral eye movements. In: Davies G, Wright D, eds. Current Issues in Applied Memory. London: Psychology Press, 2010.

24. Lyle KB, McCabe DP, Roediger HL. Handedness is related to memory via interhemispheric interaction: evidence from paired associate recall and source memory tasks. Neuropsychology 2008;22:523-30.

25. Propper RE, Christman SD, Phaneuf KA. A mixed-handed advantage in episodic memory: a possible role of interhemispheric interaction. Mem Cognit 2005;33:751-7.

26. Martin M, Papadatou-Pastou M, Jones GV, et al. Sex and location as determinants of handedness: reply to Vuoksimaa and Kaprio (2010) Psychol Bull 2010;136:348-50.

27. Strand S, Deary IJ, Smith P. Sex differences in cognitive abilities test scores: a UK national picture. Br J Educ Psychol 2006;76:463-80.

28. Duncan GJ, Brooks-Gunn J, Klebanov PK. Economic deprivation and early childhood development. Child Dev 1994;65:296-318.

29. Ribases M, Bosch R, Hervas A, et al. Case-control study of six genes asymmetrically expressed in the two cerebral hemispheres: association of BAIAP2 with attention-deficit/hyperactivity disorder. Biol Psychiatry 2009;66:926-34.

30. Shaw P, Lalonde F, Lepage C, et al. Development of cortical asymmetry in typically developing children and its disruption in attention-deficit/hyperactivity disorder. Arch Gen Psychiatry 2009;66:888-96.

31. Hirnstein $M$, Leask $S$, Rose J, et al. Disentangling the relationship between hemispheric asymmetry and cognitive performance. Brain Cogn 2010;73:119-27.

32. Heim S, Grande M, Meffert E, et al. Cognitive levels of performance account for hemispheric lateralisation effects in dyslexic and normally reading children. Neuroimage 2010;53:1346-58.

33. Salvesen KA, Eik-Nes SH. Ultrasound during pregnancy and subsequent childhood non-right handedness: a meta-analysis. Ultrasound Obstet Gynecol 1999;13:241-6.

34. Ross G, Lipper E, Auld PA. Hand preference, prematurity and developmental outcome at school age. Neuropsychologia 1992;30:483-94.

35. Olsson GM, Hulting AL, Montgomery SM. Cognitive function in children and subsequent type 2 diabetes. Diabetes Care 2008;31:514-16. 